\title{
Viscous dissipation effect on laminar forced convection in a circular duct with adiabatic walls - preliminary numerical investigation
}

\author{
Tomasz Janusz Teleszewski ${ }^{1, *}$ \\ ${ }^{1}$ Department of HVAC Engineering, Faculty of Civil and Environmental Engineering, Bialystok University of Technology, Wiejska 45A, \\ 15-351 Bialystok, Poland
}

\begin{abstract}
In this work, an analysis of laminar forced convection in a pipe with heated and adiabatic walls for a Newtonian fluid with constant properties is performed by taking the viscous dissipation into account when the axial heat conduction in the fluid is neglected. The Nusselt number versus the Brinkmann, which is based on the total wall heat flux density, have been investigated. In order to determine the temperature field, an analytical solution describing the velocity field in the pipe was used, while the energy equation was determined by the boundary element method (BEM). The results of the calculations of Nusselt numbers as a function of the Brinkman number for different thermal insulation heights to the diameter of the circular duct were presented in the form of diagrams.
\end{abstract}

\section{Introduction}

Forced convection in ducts is fundamental in heat transfer in many different systems, such as solar energy collection, nuclear heating, microflow sensors, heat exchangers and cooling of electronic devices. Research on issues related to convection forced by various channels showed that the effect of viscous dissipation cannot be neglected in the case of a number of applications, such as flows in microchannels and micro exchangers. The effect of viscous dissipation in the laminar flow of forced convection through channels is the subject of many studies. The first studies on the effect of viscous dissipation of a Newtonian fluid flow through circular tubes were made by Brinkman [1]. Numerical studies on the effect of viscous dissipation in the laminar convection of a forced Newtonian fluid in circular ducts for various boundary conditions are widely described in the literature for different boundary conditions, e.g. for a constant wall temperature [2-4] on the duct wall, for a constant heat flux [3-5] and for a periodic wall temperature or wall heat flux [6-10]. Investigations on laminar forced convection in a noncircular duct, for a Newtonian fluid at constant properties, by taking into account the viscous dissipation effect, have been presented in the literature [2, 11-17]. Several studies have focused specifically on the viscous dissipation effects for laminar forced convection of power-law fluids [18-22] and a Bingham fluid [23-28] under different thermal boundary conditions in circular ducts.

In the construction of micro-heat exchangers, adiabatic walls are often built-in. Examples of laminar flow analysis in forced convection through non-circular ducts with adiabatic walls are presented in the literature [11, 12, 29-32]. In the literature, no studies on the effect of viscous dissipation in laminar convection forced by circular pipes with adiabatic walls were found. The aim of the publication is to preliminarily study the effect of viscous dissipation through a circular tube where the height of thermal insulation $s$ (adiabatic wall) is described by the dependence (Fig. 1):

$$
\sigma_{(s / D)}=\frac{s}{D}
$$

where $D$ is the diameter of the pipe.

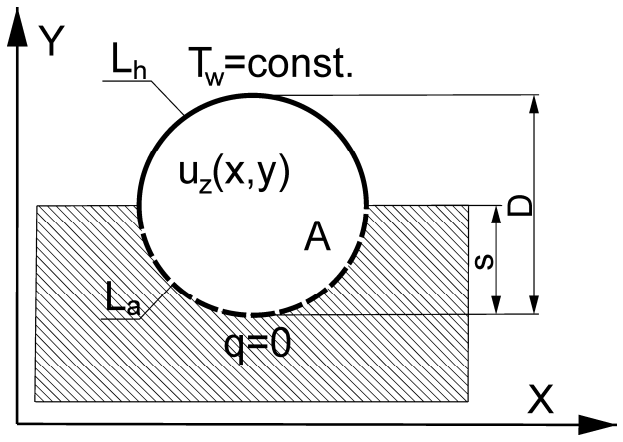

Fig. 1. Geometry of physical problem and boundary conditions.

\section{Mathematical formulation}

The presented problem of laminar forced convection in laminar flow through any duct with viscous dissipation is described by the continuity (2), momentum (3) and the

\footnotetext{
* Corresponding author: t.teleszewski@pb.edu.pl
} 
conservation of the energy equation (4) with the consideration of the viscous dissipation term $\Phi(5)$ :

$$
\begin{gathered}
\frac{\partial \mathrm{u}_{z}}{\partial z}=0 \\
\mu\left(\frac{\partial^{2} \mathrm{u}_{z}}{\partial x^{2}}+\frac{\partial^{2} \mathrm{u}_{z}}{\partial y^{2}}\right)=\frac{\partial p}{\partial z}, \quad \frac{\partial p}{\partial x}=\frac{\partial p}{\partial y}=0 \\
k\left(\frac{\partial^{2} T}{\partial x^{2}}+\frac{\partial^{2} T}{\partial y^{2}}\right)=\rho c_{p} \frac{\partial T}{\partial z} \mathrm{u}_{z}+\Phi(x, y) \\
\Phi(x, y)=\mu\left[\left(\frac{\partial u_{z}}{\partial x}\right)^{2}+\left(\frac{\partial u_{z}}{\partial y}\right)^{2}\right]
\end{gathered}
$$

where $u_{z}$ is the axial velocity, $p$ is the pressure, $\mu$ is the dynamic viscosity, $T$ is the temperature, $k$ is the thermal conductivity, $c_{p}$ is the specific heat and $\rho$ is the density. The solution of equation (3) is a well-known velocity profile for fully developed circular duct flow in cylindrical coordinates:

$$
u_{z}(r)=\frac{d p}{d z} \frac{1}{4 \mu}\left(r_{o}^{2}-r^{2}\right)
$$

where $r_{0}=D / 2$ is the radius of the pipe, $r$ is the cylindrical coordinates and $d p / d z$ is the pressure gradient.

The axial gradient $d T / d z$ is independent of $x$ and $y$. The differential equation (4) includes the temperature condition and the heat flux density condition, and it neglects the axial heat conduction in the fluid. In this work, equation (4) is subjected to the following boundary conditions for the adiabatic wall $\left(L_{a}\right)$ and heat wall $\left(L_{h}\right)$, respectively:

$$
\begin{gathered}
q=-k \frac{\partial T}{\partial n}=0, \text { at } L_{a} \\
T=\text { const., at } L_{h}
\end{gathered}
$$

\section{Results and analysis}

The field of velocity $u_{z}(x, y)$ was determined analytically from equation (6), while the temperature field $T(x, y)$ was determined by the boundary element method for 5000 linear boundary elements. The description of the solution of the energy equation using the boundary element method (BEM) can be found in $[17,33]$.

The representation of the viscous heating effect is the Brinkman number, which is based on the wall heat flux density, is given by

$$
\mathrm{Br}_{q}=\frac{\mu u_{m}^{2}}{D q_{t o t}}
$$

where $D$ is the diameter of the pipe and the mean velocity is defined as

$$
u_{m}=\frac{1}{A} \iint_{A} u_{z}(x, y) d A
$$

where $A$ is the cross-section area of the pipe and the total wall heat flux density is defined as

$$
q_{\text {tot }}=\frac{1}{L_{h}} \int_{L_{h}} q d L_{h}
$$

The Nusselt number is equal to

$$
\mathrm{Nu}=\frac{q_{t o t} D}{k\left(T_{w}-T_{b}\right)}
$$

where $T_{w}$ is the wall temperature on the boundary of $L_{h}$, while $T_{b}$ is the value of the fluid bulk temperature, which is described by dependence

$$
T_{b}=\frac{1}{A u_{m}} \iint_{A} u_{z}(x, y) T(x, y) d A
$$

Figure 2 shows examples of the graphical results of calculations of Nusselt numbers as a function of the Brinkman number for $\sigma_{(s / D)}=0$ and $\sigma_{(s / D)}=0.7$. The trends and shape of the function of the Nusselt number dependence on the number of Brinkman for various geometric parameters $\sigma_{(s / D)}$ are similar to those of $\mathrm{Nu}=\mathrm{f}(\mathrm{Br})$ presented in $[3,4,8-17,30]$. The dependencies $\mathrm{Nu}=\mathrm{f}(\mathrm{Br})$ are characterised by the creation of singular points in which the temperature difference between the wall temperature and the fluid bulk temperature $\left(\Delta T=T_{w^{-}}\right.$ $T_{b}$ ) changes its sign from positive to negative and the heat flux supplied by the wall is balanced by viscous dissipation.

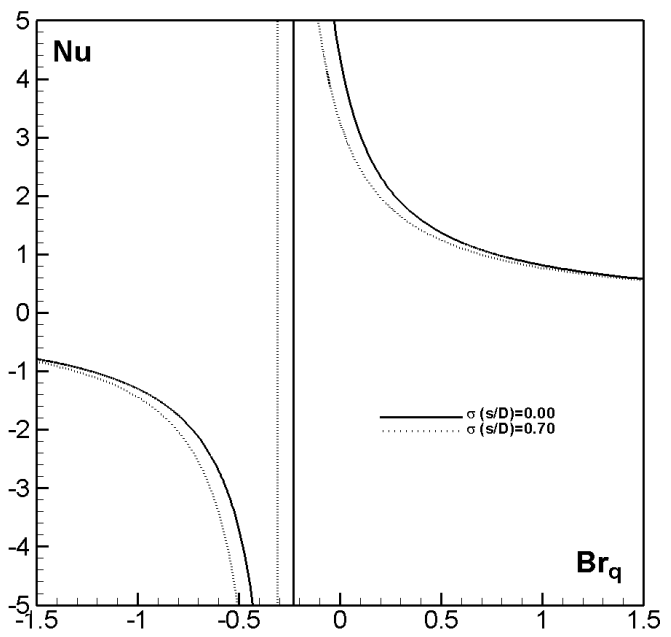

Fig. 2. The influence of $\mathrm{Br}_{\mathrm{q}}$, on the $\mathrm{Nu}$ with $\sigma_{(s / D)}$.

The dimensionless temperature distribution in the cross-section of the circular duct is obtained from the following formula

$$
\theta=\frac{T}{\left|T_{b}\right|}
$$


a)

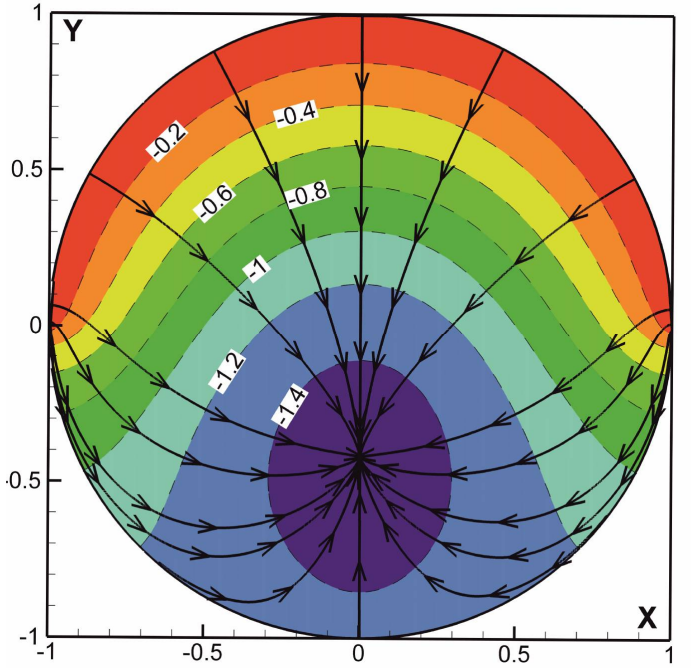

b)

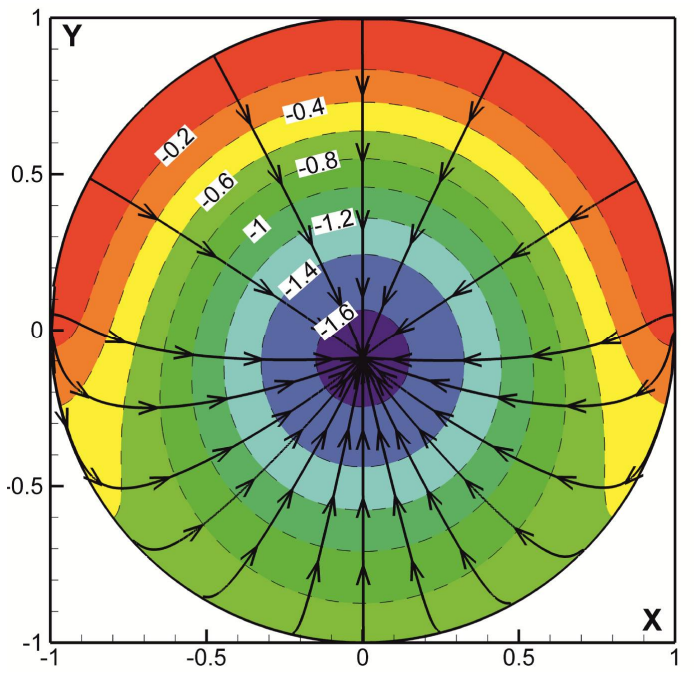

c)

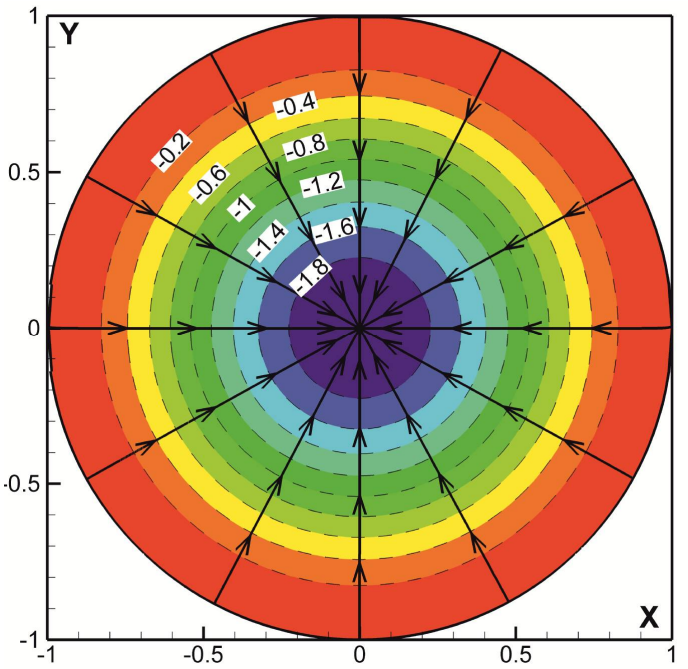

Fig. 3. Heatlines and dimensionless temperature $\theta$ obtained from the BEM solution in a circular duct with an adiabatic side $\left(\sigma_{(s / D)}=0.5\right)$, for different values of Brinkman $\left(\mathrm{Br}_{\mathrm{q}}\right)$ and Nusselt number (Nu): (a) $\mathrm{Br}_{q}=0.03, \mathrm{Nu}=3.18$; (b) $\mathrm{Br}_{q}=0.31, \mathrm{Nu}=1.68$; (c) $\mathrm{Br}_{4}= \pm \infty, \mathrm{Nu}=0$. a)

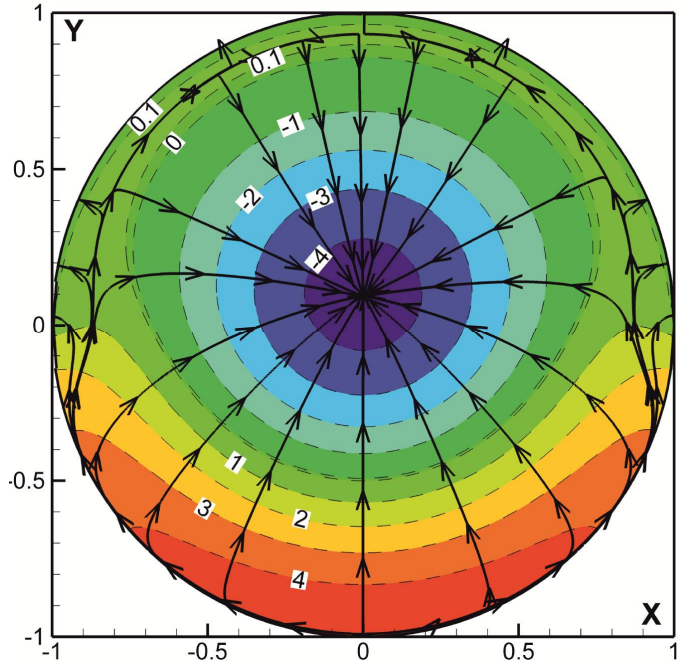

b)

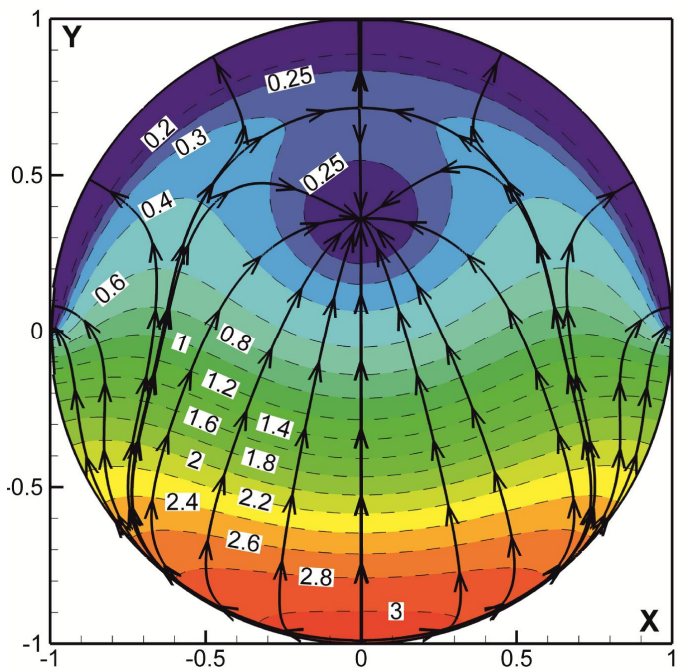

c)

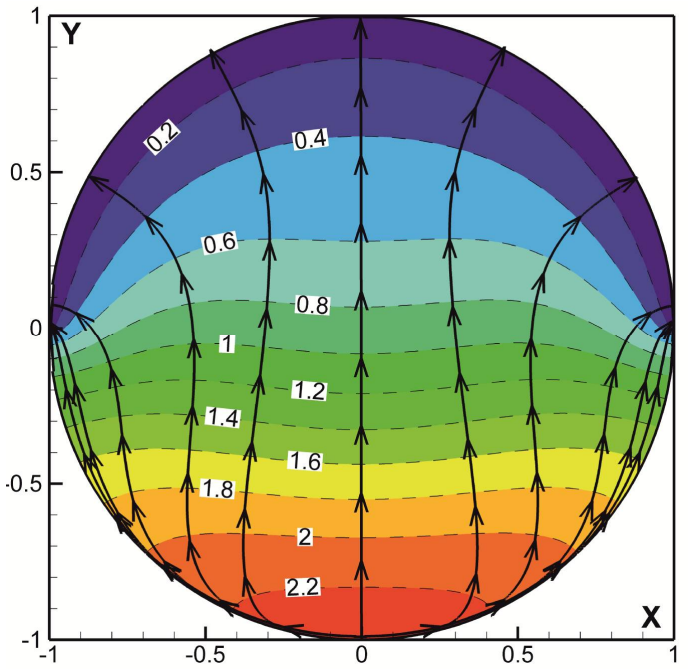

Fig. 4. Heatlines and dimensionless temperature $\theta$ obtained from the BEM solution in a circular duct with an adiabatic side $\left(\sigma_{(s / D)}=0.5\right)$, for different values of Brinkman $\left(\mathrm{Br}_{q}\right)$ and Nusselt number (Nu): (a) $\mathrm{Br}_{q}=-0.38, \mathrm{Nu}=-10.61$; (b) $\mathrm{Br}_{q}=-0.14$, $\mathrm{Nu}=6.98 ;(\mathrm{c}) \mathrm{Br}_{\mathrm{q}}=-0.1, \mathrm{Nu}=5.19$. 
The dimensionless distribution and the heatlines through the circular tube for laminar forced convection in a circular duct by taking into account the effect of viscous dissipation for $\sigma_{(s / D)}=0.5$ are shown in Figs. 3a-c and $4 \mathrm{a}-\mathrm{c}$. The point of minimum temperature departs from the adiabatic side and vanishes on the heated perimeter when the flux production by viscous forces increases. As is well known, as the rate of shear is stronger near the wall region, the thermal energy generated due to viscous dissipation is more pronounced near the wall region compared to the central region of the circular tube. Fig. 3c refers to the case when the Nusselt number is equal to zero and the wall heat flux is equal to the wall heat flux generated by viscous dissipation $\left(\mathrm{Br}_{\mathrm{q}} \rightarrow \pm \infty\right)$; it is interesting to note that the minimum point of temperature is located is in the centre of a circular pipe.

\section{Conclusions}

The effect of viscous dissipation of laminar forced convection in circular ducts with heated and adiabatic walls, under the assumption that the axial conduction in the fluid can be neglected, has been studied. As the main geometric parameter, the ratio of the thermal insulation height to the pipe diameter was adopted. In order to determine the temperature fields in the cross-section of the circular pipe, the analytical equation of the velocity field in the pipe was used, and the energy equation was solved with the boundary element method. The shapes of the determined variation of Nusselt's number from the number of Brinkman for different insulation height ratios to the pipe diameter are similar to each other. The points of singularities in the dependences of the Nusselt number in the function of the Brinkman number are also observed. The publication presents examples of solutions of temperature fields in the cross-section of a circular pipe.

\section{Acknowledgements}

This scientific project was financed within the framework of science research S/WBiIS funds at the Bialystok University of Technology.

\section{References}

1. H.C. Brinkman, Appl. Sci. Res. 2, 120 (1951)

2. V.P. Tyagi, J. Heat Transfer 88(2), 161 (1996)

3. O.A. Aydin, Energ. Conver. Manage. 46, 757 (2005)

4. O.A. Aydin, Energ. Conver. Manage. 46, 3091 (2005)

5. E. Zanchini, Int. J. Heat Mass Transfer 40(1), 169 (1997)

6. C-J. Hsu, A.I.Ch.E. Journal 11(4), 690 (1965)

7. J.N.N. Quaresma, R.M. Cotta, Int. Commun. Heat Mass 21(5), 729 (1994)
8. D-Y Lee, S-J Park, S.T. Ro, Int. J. Heat Mass Transfer 38(14), 2529 (1995)

9. A. Barletta, E. Zanchini, Heat and Mass Transfer 31(1), 41 (1995)

10. A. Barletta, E. Rossi di Schio, Heat and Mass Transfer 35(1), 9 (1999)

11. G.L. Morini, M. Spiga, J. Heat Transfer 121(4), 1083 (1999)

12. G.L. Morini, M. Spiga, J. Heat Transfer, 129(3), 308 (2007)

13. G.L. Morini, M. Spiga, P. Tartarini, Int. Comm. Heat Mass Transfer 25(4), 551 (1998)

14. M. Avci, O.A. Aydin, C.R. Mecanique 324, 164 (2006)

15. T.J. Teleszewski, S. A. Sorko, Procedia Engineering 157, 171 (2016)

16. T.J. Teleszewski, IOP Conf. Ser.: Mater. Sci. Eng. 269, 012038 (2017)

17. T.J. Teleszewski, S.A. Sorko, International Journal of Numerical Methods for Heat \& Fluid Flow 28(1), 220 (2018)

18. A. Barletta, Int. J. Heat Mass Transf. 40(1), 15 (1982)

19. A. Lawal, A.S. Mujumdar, Wärme - und Stoffübertragung 27(7), 437 (1992)

20. T. Boaca, I. Boaca, Trans. on Comput. Sci. I, LNCS 4750, 139 (2008)

21. A.M. Dehkordi, A.A. Mohammadi, Energ. Conver. Manage. 50(4), 1062 (2008)

22. A.M. Dehkordi, A.A. Mohammadi, Energ. Conver. Manage. 51(5), 1065 (2010)

23. G.C. Vradis, J. Dougher, S. Kumar, Int. J. Heat Mass Transf. 36(3), 543 (1993)

24. T. Min, J.Y. Yoo, H. Choi, Int. J. Heat Mass Transf. 40(13), 3025 (1997)

25. T. Min, H.G. Choi, J.Y. Yoo, H. Choi, Int. J. Heat Mass Transf. 40(15), 3689 (1997)

26. T. Min, J.Y. Yoo, J. Heat Transfer 121(3), 556 (1999)

27. R. Khatyr, D. Ouldhadda, A. Il Idrissi, Comptes Rendus Mecanique 330(2), 69 (2002)

28. R. Khatyr, D. Ouldhadda, A. Il Idrissi, Int. J. Heat Mass Transf. 46(4), 589 (2003)

29. F. W. Schmidt, M.E. Newell, Int. J. Heat Mass Transf. 10, 1121 (1967)

30. M. Spiga, G.L. Morini, Int. J. Heat Mass Transf. 39(6), 1165 (1996)

31. G.L. Morini, Int. J. Heat Mass Transf. 43(5),741 (2000)

32. V.V. Dharaiya, S.G. Kandlikar, J. Heat Transfer 134(2) (2012)

33. C.A. Brebbia, J.C.F. Telles, L.C. Wrobel, Boundary Element Techniques-Theory and Applications in Engineering (1984) 